\title{
Reproductive Indices of Rainbow Trout (Oncorhynchus mykiss) Females from a Trout Farm
}

\author{
Andrada IHUȚ̦i ${ }^{1)}$, Vioara MIREŞAN ${ }^{1) *}$, Daniel-Ioan $\operatorname{COCAN}^{11}$, Camelia RĂDUCU ${ }^{1)}$, Călin LAȚIU $^{11}$, Denisa \\ $\mathrm{POP}^{1)}$ \\ 1) Faculty of Animal Science and Biotechnologies, University of Agricultural Sciences and Veterinary \\ Medicine of Cluj-Napoca, 3-5 Manastur Street, 400372, Cluj-Napoca, Romania \\ *Corresponding author, e-mail: vmiresan@yahoo.com
}

Bulletin UASVM Animal Science and Biotechnologies 72(2) / 2015

Print ISSN 1843-5262; Electronic ISSN 1843-536X

DOI:10.15835/buasvmcn-asb:11537

\begin{abstract}
Rainbow Trout (Oncorhynchus mykiss) breeding females have been studied from the standpoint of phenotypic characteristics and breeding indices for establishing future protocols of selection and improvement. The relative fecundation (RF) has been determined to a medium value of $335.88 \pm 17.723 \mathrm{~g}$ and a variability coefficient of $52.77 \%$. The high value of the variability coefficient is due to the fact that this is the first breeding generation of trout nursery and has not been submitted to any selection and improvement activities up to the present. From the breeding performance standpoint, the medium value of the number of eggs (TNE) obtained has been of 8127.44 \pm 478.532 , the medium egg weight (EW) has been of $0.06 \pm 0.001 \mathrm{~g}$, the medium diameter of one egg (ED) $=4.16 \pm$ $0.029 \mathrm{~mm}$ and the medium volume of one egg (EV) has been of $65.63 \pm 1.223 \mathrm{~mm}$. The following breeding indices have also been calculated: gonadosomatic report (GR), Behning fertilizing coefficient (BFC) and the Williams absolute fecundity indices (WAFI). The outcome results have been the following: $\mathrm{GR}=14.82 \pm 0.587 ; \mathrm{BFC}=16.82$ \pm 0.563 ; WAFI $=5.77 \pm 0.333$. The values of the correlations point out the necessity of breeding selection work in order to improve the breeding performances.
\end{abstract}

Keywords: Rainbow Trout, improvement, breeding selection.

\section{INTRODUCTION}

Rainbow Trout (Oncorhynchus mykiss) is one of the most raised species of the Salmonidae family, due to its adaptive abilities to the intensive growing system (Bud et al., 2007). In Romania there are few salmonid units where rainbow trout is artificially bred, due to this fact it is necessary to streamline their technological and economic activities based on a selection-broodstock programme (Cocan et al., 2013).

Breeding is one of the most important aspects of the technological growing flow in a Salmonid unit, being influenced by factors such as genetics, environmental conditions, and nutrition (Kausea et al., 2005). Broodstock production is influenced by age, weight and conformation (Kayam, 2004). Their quality is directly reflected on offspring survival rate, growth performance and resistance to disease. Thus the breeding stock requires selection methods for a rigorous selection (Mireşan et al., 2013).

Selection methods for improving the breeders can use correlations between phenotypic characters and breeding indices to obtain valuable batches of breeding However correlations between breeding indices and somatic characteristics are few in scientific literature (Cocan et al., 2013).Therefore the aim of this study was to select the breeding females based on individual performance for obtaining batches of breeders with superior performance, above average and to correlate the reproductive indices with morpho-productive measurements for improving and selection of the future female breeding stock. 


\section{MATERIALS AND METHODS}

This study was performed in February 2015, on the first breeding generation of the fishery. Reproduction performances were determined on 16 randomly selected rainbow trout (Oncorhynchus mykiss) female breeding stock (Ibw-initial body weight; Fbw-final body weight; RF -relative fecundity; TNE - eggs total number; Ew-eggs weight; Ed-eggs diameter; Ev-eggs volume) necessary and useful for calculating the reproduction indices: GR - gonadosomatic report, BFC - Behning fertilizing coefficient and the WAFI Williams absolute fecundity indices (Turliu, 2008).

Reproductive indices were calculated after the following formulas:

Gonadosomatic report $=\frac{\text { ovary weight } \times 100}{\text { body weight }}$

Behningfertilizingcoefficient $=\frac{\text { body length } \times 100}{\text { total number of eg.gs }}$

Williams absolute fecundity indices = $\frac{\text { gonadosomatic report } \times \text { body weight }}{\text { the average weight of an eg } \mathrm{x} \times 100}$

The purpose of the study was to test whether there is are any phenotypic correlations between somatic characteristics and breeding characteristics, so that in the future, selection for improved reproductive performance can be done based on one of two phenotypic correlated characteristics.

Afterwards, the existing correlations between the studied somatic characteristics: (Bw -body weight, $\mathrm{Tl}$ - total length, $\mathrm{Sl}$ - standard length, $\mathrm{Cl}$ commercial length, $\mathrm{MH}$ - maximum height, $\mathrm{Mh}$ minimum height, $\mathrm{Bd}$ - body depth, $\mathrm{Hl}$ - head length, $\mathrm{Cpl}$ - caudal peduncle length) and the reproduction indices previously mentioned shows close links between somatic characters and reproductive indices.

Nutrition as well is an important factor for reproductive performance, therefore the female breeding stock were fed according to the requirements (Tab. 1) starting with the first stage of growth. All data was statistically analysed with add - In Data analysis from Microsoft Excel. Correlations were performed with Pearson Correlation.

\section{RESULTS AND DISCUSSION}

The breeding rainbow trout (Oncorhynchus mykiss) females aged 3 years from fishery, have been studied for both production performance and reproduction indices.

Based on the samples and weighing before and after spawning, the relative fecundity (RF) has been determined to a value of $335.88 \pm$ $17.723 \mathrm{~g}$ with a variability coefficient of $52.77 \%$. The high variability coefficient is due to the fact that this was the first breeding generation in the fishery obtained from own nursery without being subjected to selection and improvement activities. (Tab. 2)

The total number of eggs (TNE) and egg diameter (Ed) are the most frequently used criteria in production, as the increase in broodstock weight directly influences the increase in the number and diameter of eggs (Bromage and Cumaranatunge, 1988).

The total number of eggs (TNE) value was $8127.44 \pm 478.532$, higher than that obtained by Kayam, (2004) but with greater variability coefficient, of $58.88 \%$, therefore for the future reproduction nucleus, we will choose those

Tab. 1. Composition and nutritive value of the administered fodder

\begin{tabular}{cccc}
\hline \multirow{2}{*}{ Issue } & \multicolumn{3}{c}{ Fodder Type } \\
\cline { 2 - 4 } & Aqua Dynamic 2 mm & Aqua Dynamic 3 mm & Aqua Dynamic 4/6 mm \\
\hline Crude protein \% & 43 & 41 & 40 \\
\hline Crude fat \% & 20 & 21 & 22 \\
\hline Cellulose \% & 2.0 & 2.2 & 1.35 \\
\hline Phosphorus \% & 1.20 & 1.30 & 10000 \\
\hline Vitamin A (UI/kg) & 10.000 & 10000 & 1500 \\
\hline Vitamin D3 (UI/kg) & 1500 & 1500 & 200 \\
\hline Vitamin E $(\mathrm{mg} / \mathrm{kg})$ & 200 & 200 & 20.0 \\
\hline Convertible energy (Kcal/MJ) & 20.0 & 19.8 & \\
\hline
\end{tabular}


individuals that produce the richest spawn. Also some of the most important factors that affect egg production at rainbow trout (Oncorhynchus mykiss) are consanguinity among breeding stock, age and weight, quality of feed and water quality (Billard, 1990; Bromage et al., 1992, Ozgur and Bayir, 2013).

In the present study, we found that the egg weight $(\mathrm{Ew})$ was $0.06 \pm 0.001 \mathrm{~g}$, and the egg diameter (Ed) was $4.16 \pm 0.029 \mathrm{~mm}$, while for the egg diameter, Özgür and Bayir (2013) obtained $5.58 \pm 0.18 \mathrm{~mm}$ at four year old female broodstocks, and for the same age, Kocaman et al. (2009) obtained almost the same value (5.33 \pm 0.10 ). From this data, we can conclude that the number and diameter of eggs increase with the age of broodstocks.

The following reproduction indices: GR gonadosomatic report, BFC - Behning fertilizing coefficient and the WAFI - Williams absolute fecundity indices have also been calculated.

The egg volume (Ev) was $65.63 \pm 1.223 \mathrm{~mm}^{3}$. Also the gonadosomatic report (GR) presented values of $14.82 \pm 0.587$ lower than the one obtained by Mireşan et al. (2013) of $15.218 \pm$ 0.438 on 4 year-old females, and Bud et al., (2009) of $22.54 \pm 1.13$; therefore we concluded that for the future breeding stock only the females who have the greater gonadosomatic report (GR) will be selected. As other authors mentioned the breeding performance of rainbow trout and others trout females species increase with the age, reaching maximum performance at 6-8 years (Cocan et al., 2013; Rahbaret al., 2011). The batch of studied female in this paper was three years old, at the beginning of reproductive period.

Behning fertilizing coefficient (BFC) was $16.82 \pm 0.563$ with a variability of $33.48 \%$; the increasing values of Behning coefficient indicate a gradual and proportional increase of total number eggs (TNE) simultaneously with age (Mireşan et al., 2013). Also Williams absolute fecundity (WAFI) is directly proportional with the females' age and recorded a value of $5.77 \pm 0.333$, higher than $4.278 \pm 0.279$ found by Mireşan et al.(2013) at the same female age.

Gonadosomatic report (GR) presented strong and positive correlation $(r=0.621)$ with maximum height $(\mathrm{MH})$ and initial body weight (Ibw), where the correlation value was 0.415 , lower than that obtained by Cocan et al. (2013) at the same female age. The values of the correlation coefficients indicate that the selection can be performed for the improvement of the characteristic for which the higher correlation value was found.

Also Gonadosomatic report (GR) presented a negative correlation for total length ( $\mathrm{Tl})(\mathrm{r}$ $=-0.116)$ lower than that obtained by Cocan et al. (2013) ( $\mathrm{r}=-0.027)$, who point out that along with the increase of total length $(\mathrm{Tl})$ the values of coefficients and indices of selection and breeding are decreasing.

Behning fertilizing coefficient (BFC) presented positive value for total length ( $\mathrm{Tl})(\mathrm{r}=0.264)$, a value higher than that found by Cocan et al. (2013) $(r=0.130)$, and negative correlation between BFC and the initial body weight $(r=-0.258)$.

Williams absolute fecundity index (WAFI) presented strong and positive value for maximum height $(r=0.635)$ and initial body weight $(r=0.562)$, lower than that obtained by Cocanet al. (2013) (0.953); The values of the correlation coefficients indicate that the selection can be performed for the improvement of the characteristic in female breeders for which the higher correlation value was found, between maximum height and initial body weight. Also negative correlations were obtained for total length $(\mathrm{Tl})(\mathrm{r}=-0.054)$, as

Tab. 2. The mean values of meristic and gravimetric measurement of rainbow trout (Oncorhynchus mykiss) female at age of three years.

\begin{tabular}{|c|c|c|c|c|c|c|c|c|c|c|}
\hline Sp. & Ibw/g & $\mathrm{Fbw} / \mathrm{g}$ & $\mathrm{RF} / \mathrm{g}$ & TNE & Ew/g & $\mathrm{Ed}(\mathrm{mm})$ & $\mathrm{Ev}\left(\mathrm{mm}^{3}\right)$ & GR & $\mathrm{BFC}$ & WAFI \\
\hline $\mathrm{X} \pm \mathrm{sx}$ & $2208.38 \pm 37.48$ & $1872.5 \pm 29.556$ & $335.88 \pm 17.723$ & $8127.44 \pm 478.532$ & $0.06 \pm 0.001$ & $4.16 \pm 0.029$ & $65.63 \pm 1.223$ & $14.82 \pm 0.587$ & $16.82 \pm 0.563$ & $5.77 \pm 0.333$ \\
\hline V\% & 16.97 & 15.78 & 52.77 & 58.88 & 16.76 & 7.02 & 18.64 & 39.58 & 33.48 & 57.67 \\
\hline S & 374.795 & 295.562 & 177.233 & 4785.321 & 0.010 & 0.292 & 12.230 & 5.867 & 5.631 & 3.327 \\
\hline \multirow{2}{*}{ Range } & Max & Max & Max & Max & Max & Max & Max & Max & Min $\quad$ Max & Max \\
\hline & $1705 \quad 2825$ & $1510 \quad 3475$ & 130900 & 351324324 & $0.04 \quad 0.08$ & 4.51 & 80 & $7.49 \quad 31.86$ & $6.13 \quad 27.16$ & $\begin{array}{ll}2.88 & 17.19\end{array}$ \\
\hline
\end{tabular}


Tab. 3. Phenotypic correlation coefficient values of the morphological reproductive performance at rainbow trout (Oncorhynchus mykiss).

\begin{tabular}{cccccccccc}
\hline Specif. & Fbw & RF & TNE & Ew & Ed & Ev & GR & BFC & WAFI \\
\hline Ibw & 0.887 & 0.636 & 0.593 & 0.288 & 0.230 & 0.092 & 0.415 & -0.258 & 0.562 \\
\hline Tl & 0.350 & 0.018 & -0.012 & 0.194 & 0.141 & -0.136 & -0.116 & 0.264 & -0.054 \\
\hline Sl & 0.379 & 0.101 & 0.060 & 0.318 & 0.252 & -0.020 & -0.027 & 0.165 & -0.002 \\
\hline Cl & 0.454 & 0.070 & 0.030 & 0.334 & 0.242 & 0.045 & -0.061 & 0.148 & -0.312 \\
\hline MH & 0.585 & 0.752 & 0.696 & 0.450 & 0.294 & 0.275 & 0.621 & -0.510 & 0.635 \\
\hline Mh & 0.578 & 0.104 & 0.070 & 0.282 & 0.362 & -0.087 & -0.048 & 0.094 & 0.033 \\
\hline Bd & 0.520 & 0.579 & 0.583 & 0.152 & -0.0002 & 0.247 & 0.432 & -0.331 & 0.559 \\
\hline HL & 0.416 & 0.067 & 0.015 & 0.430 & 0.412 & 0.336 & -0.020 & 0.080 & -0.045 \\
\hline CpL & -0.095 & 0.162 & 0.152 & -0.085 & -0.060 & 0.021 & 0.137 & 0.001 & 0.158 \\
\hline
\end{tabular}

(Ibw) initial body weight, (Fbw) final body weight; (RF) relative fecundity, (TNE) eggs total number, (Ew) eggs weight, (Ed) eggs diameter, (Ev) eggs volume, (GR) gonosomatic report, (BFC) Behning fertilizing coefficient (WAFI) Williams absolute fecundity indices, (Tl) total length, (Sl) standard length, $(\mathrm{Cl})$ commercial length, $(\mathrm{MH})$ maximum height, $(\mathrm{Mh})$ minimum height, (Bd) body depth, (HL) head length, (CpL) caudal peduncle length.

opposed to the positive correlation obtained by Cocan et al. (2013) ( $\mathrm{r}=0.162)$, showing again the necessity of further analysis to obtain accurate results.

Strong and positive correlations were obtained for the following characteristics: between final body weight (Fbw) and initial body weight (Ibw) ( $r$ = 0.887); as expected, relative fecundity (RF) and maximum height $(\mathrm{MH})(\mathrm{r}=0.752)$; as well as between total number eggs (TNE) and maximum height $(\mathrm{MH})(\mathrm{r}=0.696)$.

In conclusion, the present correlations are useful for selection of the future female breeders starting with the first year of reproduction for obtaining of the quantitatively and qualitatively best egg production, for the entire optimal reproduction age range.

\section{CONCLUSION}

The resulting values of the correlations show strong interdependencies between morphoproductive measurements and reproduction indices of fertility; therefore in the breeding stock we must take into account to select the females who show the greatest value for initial body weight to increase the total number eggs (TNE), eggs weight (Ew) and reproduction indice performances. This study can contribute to increasing fish production and reproduction performance in Romanian rainbow trout fisheries.

Acknowledgments. This paper was published under the frame of European Social
Fund, Human Resources Development Operational Program 2007-2013, project no. POSDRU/159/1.5/S/132765.

\section{REFERENCES:}

1. Billard R, (1990). Culture of salmonids in fresh water. In: G. Barnabé Ed. Aquaculture. vol. 2, Ellis Harwood Limited, London, 549592.

2. Bromage N, Cumaranatunge PRC, (1988). Egg Production in the Rainbow Trout. In RJ, Roberts JF, Muir Eds. Recent Advances in Aquaculture. Vol. 3, Croom Helm, London, 65137.

3. Bromage N, Jones J, Randall C, Thrush M, Davies B, Springate J, Duston J, Barker G, (1992). Broodstock Management, Fecundity, Egg Quality and Timing of Egg Production in the Rainbow Trout (Oncorhynchus mykiss), Aquaculture, 100: 141-166.

4. Bud I, Boaru A, Petrescu-Mag V (2009). Influence of food and age on breeding and reproductive performances in a rainbow trout population. AACL Bioflux 2(2):239-247.

5. Bud I, Ionescu O, Vlădău V, Pop S (2007). Peştii din apelereci. Păstrăvii. Ed. Risoprint Cluj-Napoca.

6. Cocan D, Mireșan V, Constantinescu R, Răducu C, Ihuț A, (2013). Correlation between Age and Fertility Indices of Rainbow Trout (Oncorhynchus mykiss) Females. Bulletin UASVM Animal Science and Biotechnologies 70 (1): 199200.

7. Kausea A, Ritolab O, PaananenbT,Wahlroosa H, Mäntysaaria EA, (2005). Genetic trends in growth, sexual maturity and skeletal deformations, and rate of inbreeding in a breeding program for rainbow trout (Oncorhynchus mykiss). Aquaculture,247: 177-187.

8. Kayam S,(2004) The Effect of Mating Different Age Groups of Broodstocks on the Reproductive performance, Sex Ratio, Growth, and Survival bate of Rainbow Trout (Oncorhynchus mykiss), Journal of Freshwater Ecology, 19 (4): 695-699. 
9. Kocaman EM, Bayir A, Sirkecioglu AH, Bayir M, Yanik T, Arslan H, (2009). Comparison of Hatchery Performances of Rainbow Trout (Oncorhynchus mykiss) Brown Trout (Salmo truttafario) and Brook Trout (Salvelinusfontinalis) under the Same Enviromental Conditions. Journal of Animal and Veterinary Advances 8 (7) : 1429_1431.

10. Mireșan V, Cocan D, Răducu C, Constantinescu R, Ihuț A, (2013). Female Fertility Curve of Rainbow Trout (Oncorhynchus mykiss) by Different Ages. Bulletin UASVM Animal Science and Biotechnologies 70 (1), 15-18
11. Özgür ME, Bayir İ., (2013). A Research on Reproduction Performance for Broodstocks of Rainbow Trout in A Fish Farm. BiyolojiBilimleriAraştırmaDergisi 6 (2): 01-07.

12. Rahbar M, Nezami Sh, Khara H, Rezvani M, Khodadoust A, Movahed R, Eslami S, (2011). Effect of age on reproductive performance in female Caspian brown trout (Salmo trutta caspious, Kessler 1877) Caspian Caspian Journal of Environmental Sciences 9 (1):97-103.

13. Turliu, GN. (2008). Piscicultura practică. Ed. Ceres, Bucuresti, 248-252. 